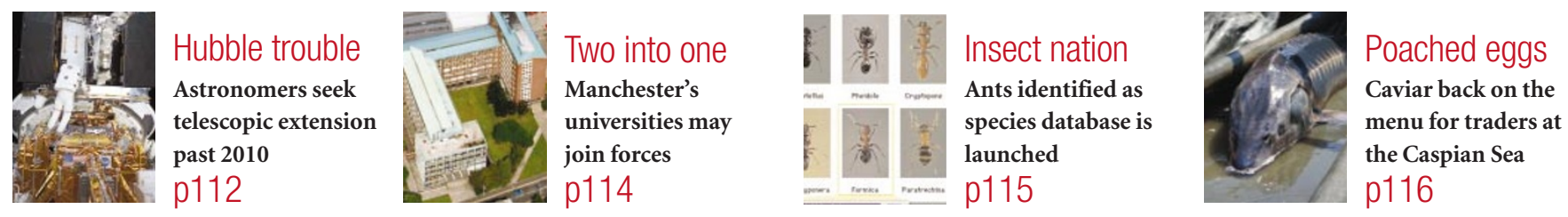

\title{
Geneticists get steamed up over public access to rice genome
}

\section{Declan Butler}

Twenty top genome researchers have written to the editorial advisers of Science protesting at the way the journal occasionally publishes genome maps without requiring the authors to place the supporting sequence data in public databases.

The letter is signed by such luminaries as Bob Waterston, head of genetics at Washington University in St Louis, Nobel laureate Aaron Klug of the MRC Laboratory of Molecular Biology in Cambridge, UK, and Michael Ashburner, former head of the European Bioinformatics Institute at Hinxton near Cambridge. In it they argue that new genome sequences should be made available in public-domain databases in line with what they term "accepted norms of the field".

"There are strong rumours in the field that Science is considering allowing the publication of papers from commercial companies on the rice and mouse genomes, without demanding the submission of the data in GenBank as a condition," their letter says.

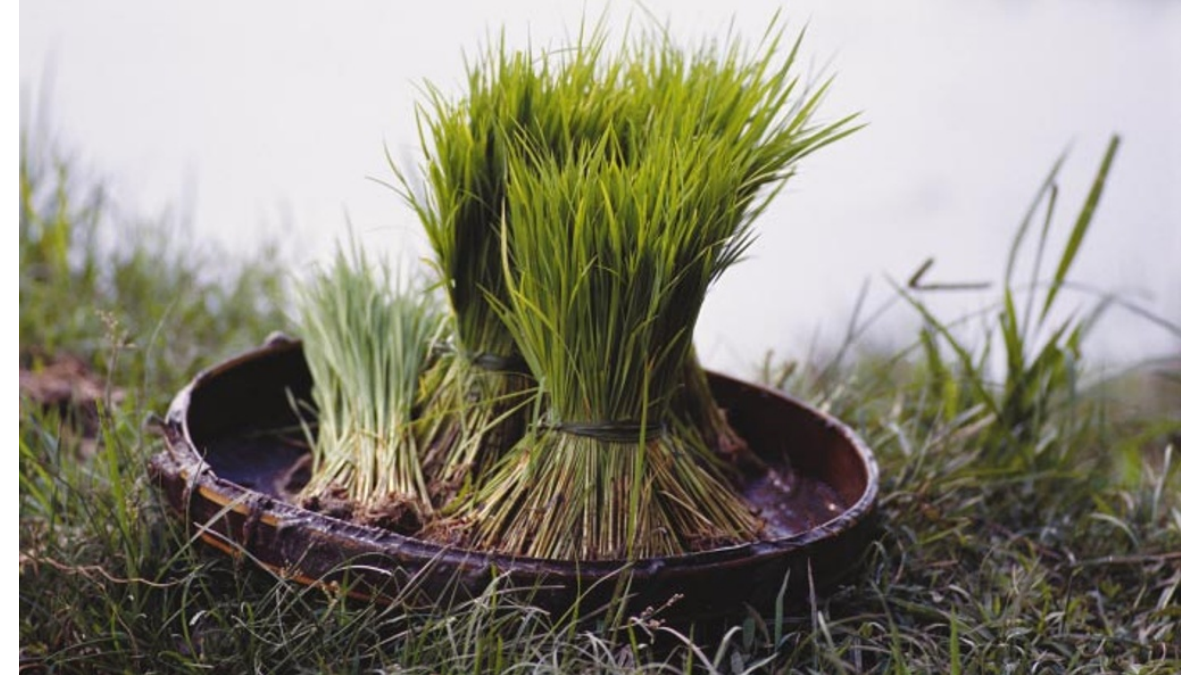

Boiling point: disputes about gene data have spilt over to the planned publication of a rice genome.

Several sources confirm that Science intends to publish a paper by the Swiss-based agricultural biotechnology company Syn-

\section{Societies query student-visa review}

\section{Geoff Brumfiel, Washington}

Scientific societies say that they have been locked out of a government task force that is drafting restrictions on the flow of international students into the United States in the wake of last autumn's terrorist attacks.

The task force on student visas is expected to release draft proposals within the next month for the entry of both undergraduate and graduate students. It is made up of officials from the White House Office of Homeland Security and the Office of Science and Technology Policy, together with representatives from the state and justice departments, which oversee immigration.

Irving Lerch, head of international affairs at the American Physical Society, says that universities and societies are not involved in the debate. "When you have such important discussions going on within the government, without the participation of those who know what the problems are, you have a prescription for disaster," he says.

Lerch fears that the final criteria will curtail recruitment from 'sensitive' countries such as India and China, which supply the United States with large numbers of graduate students.

The closed nature of the process is “of enormous concern”, says Vic Johnson, director of public policy at the Association for International Educators, a Washingtonbased group that promotes student exchanges. "Let's not go overboard and cut off scientific exchange," he says.

But the White House says that the panel's findings will be discussed with universities before they are implemented. "As soon as we have something we can share, we plan to share it," a White House official says. genta on its draft of the rice genome. The supporting sequence data will not be deposited in GenBank, the sources say, but will be available free to academic researchers from Syngenta's website, subject to certain restrictions.

Science drew criticism last year when it agreed to publish the draft human genome assembled by Celera Genomics of Rockville, Maryland, despite the company's restrictions on access to the sequence data.

Donald Kennedy, Science's editor-inchief, declines to comment on the pending paper. "Science is committed to full public access," he says. "But we will consider rare exceptions if the public benefits of removing valuable data and results from trade-secret status clearly exceed the costs to the scientific community of the precedent the exception might create. This was true for the human genome sequence, and for the most important agricultural commodity in the Third World, the case is surely even stronger."

According to several researchers, Science also plans to publish a draft sequence of Oryza sativa L. ssp. indica, the major crop rice cultivar in China, alongside the Syngenta genome. This second rice genome was completed recently by a team led by Huanming Yang, director of the Beijing Genomics Institute, and the supporting sequence 
data have been deposited in GenBank.

A draft sequence of the rice genome by the agricultural biotechnology company Monsanto, based in St Louis, Missouri, and one by Celera of the mouse genome, are also under preparation, but have not yet been scheduled for publication in any journal.

Syngenta currently makes its data available to a handful of academic groups through special agreements. The publication of Syngenta's rice genome in Science might result in changes to the company's policy, giving more researchers access to the sequence data. But, as the letter demonstrates, researchers remain deeply divided over the terms of such access. "This goes to the heart of what science is all about, the free exchange of ideas, data and reagents," says Bruce Stillman, director of the Cold Spring Harbor Laboratory in New York state. Science should not compromise on making the data freely available, he says.

But Ron Cantrell, director of the International Rice Research Institute in the Philippines, is more supportive of Science's decision to publish. "You have to ask the question 'is it better not to have any access at all?', ' he says, adding that, in his experience, Syngenta and Monsanto have "been very forthcoming" in collaborations with the public sector.

Chris Novak, a spokesman for Syngenta, says that the company hopes to work with the publicly funded International Rice Genome Sequencing Project (IRGSP). The project intends to produce a 'finished' highquality sequence, as opposed to the drafts, containing many gaps, that are about to be published.

Researchers point out that Science's agreement with Syngenta is not entirely analogous to the one it reached last year with Celera on the human genome. Celera contributed no data to the public Human Genome Project, instead relying on data from the public project to complete its own sequence. In contrast, Syngenta has already contributed significant mapping data to the IRGSP, through a collaboration with Clemson University in South Carolina.

But Syngenta has so far refused to share its raw sequence data with all of the public group - unlike its rival Monsanto, whose contributions of sequence data are credited with strongly accelerating the public project.

In January, however, Syngenta began talks with the IRGSP and, according to one IRGSP official, has agreed in principle to match the Monsanto agreement. If it does, "all the Syngenta and Monsanto data will be in the public domain by the end of the year", says the official. The likelihood of this happening might be a factor in persuading Science to accept restrictions on the rice data for the time being, observers suggest.

\section{NASA urged to play waiting game on Hubble's retirement}

\section{Tony Reichhardt, Washington}

Even as NASA completes a successful service mission on the Hubble Space Telescope, a debate is simmering in the agency about how long to keep the instrument in action.

NASA's current plan is to return the telescope to Earth in 2010 and put it in the Smithsonian National Air and Space Museum in Washington. But some Hubble-project scientists and engineers at NASA's Goddard Space Flight Center in Maryland have been arguing — albeit with little success so far - that the telescope should continue its observations.

The dilemma of when to pull the plug on a successful mission is a familiar one at NASA. But the case of Hubble will be especially difficult. Not only is it the most powerful telescope in history, but its observing grants are now established as a mainstay of support for US astronomers. And after last week's service mission - the fourth since its launch in 1990, and one which brought an infrared camera back to life and installed the powerful Advanced Camera for Surveys the telescope has never been more capable.

But NASA needs to retire Hubble to pay for its successor, the Next Generation Space Telescope (NGST). The agency has already delayed Hubble's retirement from 2005 to 2010, and is reluctant to do so again to appease those whom former NASA administrator Dan Goldin once derided as "Hubble huggers". So the current plan is for astronauts to install another camera and spectrograph during a fifth and final servicing mission in 2004, and to bring the telescope home six years later.

But project engineers at Goddard say that this will not be straightforward. Dismantling Hubble and returning it to Earth is more challenging than previously thought. The mission would require up to five spacewalks, and the telescope's weight would strain the shuttle's maximum landing limit.

NASA had hoped to launch the NGST

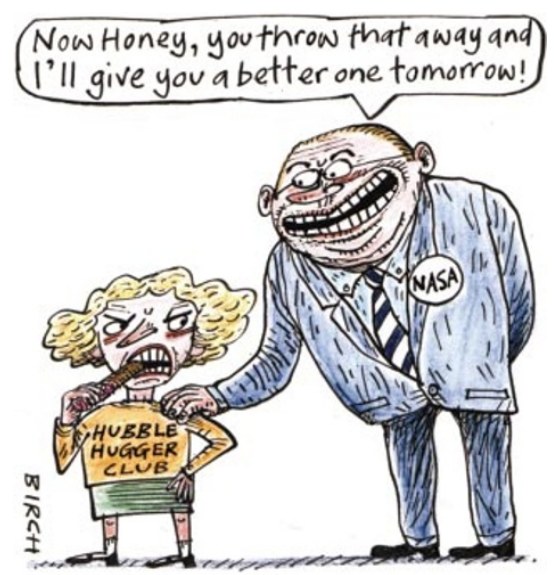

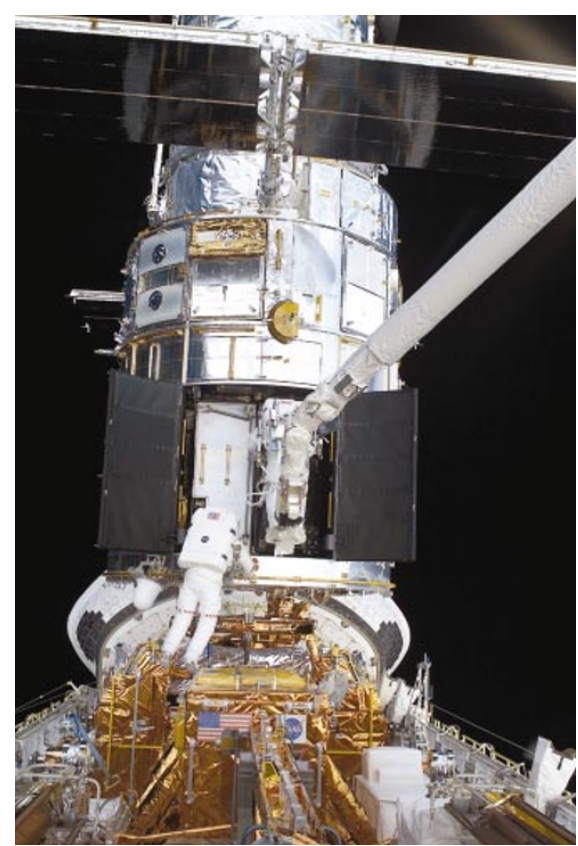

Despite the telescope's renewed capacity, NASA is reluctant to spend money on Hubble as it ages.

before Hubble retires, but the launch date has already moved from 2007 to 2009, and could easily slip further. According to Goddard engineers, Hubble is unlikely to survive six years after 2004 without maintenance.

So the Goddard team has proposed that another service mission be added in 2007. As well as making any necessary repairs, shuttle astronauts would attach a propulsion module that could allow the telescope to be 'deorbited' safely to burn up in the atmosphere.

The Air and Space Museum would lose an exhibit, but scientists would gain more Hubble viewing time. Hubble senior project scientist Dave Leckrone of Goddard, who advocates extending the telescope's life, admits it will be an uphill struggle to convince NASA. "The official position is that there will be no more servicing of Hubble after 2004," he says.

A committee representing Hubble users advised NASA last October to consider the extra servicing mission. Committee chairman George Miley of Leiden University in the Netherlands agrees that delaying the NGST would be "bad for astronomy", but adds that "the effectiveness of an extra Hubble refurbishment mission should be seen in a wider context and considered within the framework of the NASA programme as a whole".

But in a letter to Anne Kinney, director of NASA's 'Origins' programme, an advisory committee to that programme argued that "minimizing additional expenditures on [Hubble] is crucial to keep the development of NGST on track". 